\title{
Community-Based ART Service Delivery for Key Populations in Sub-Saharan Africa: Scoping Review of Outcomes Along the Continuum of HIV Care
}

\author{
Olujuwon Ibiloye ${ }^{1,2,4}\left(\right.$ D $\cdot$ Caroline Masquillier ${ }^{4} \cdot$ Plang Jwanle $^{2} \cdot$ Sara Van Belle ${ }^{1} \cdot$ Josefien van Olmen ${ }^{4} \cdot$ Lut Lynen $^{1}$. \\ Tom Decroo ${ }^{1,3}$
}

Accepted: 24 December 2021 / Published online: 17 January 2022

(c) The Author(s) 2022

\begin{abstract}
HIV positive key population (KP) often face health system and social barriers to HIV care. KP include sex workers, men who have sex with men, persons who inject drugs, transgender people, and people in prisons and other closed settings. Community-based ART service delivery (CBART) has the potential to increase access to antiretroviral treatment (ART) and enhance retention in care. This scoping review summarized the evidence on the effect of CBART along the continuum of HIV care among KP in sub-Saharan Africa. We searched Pubmed, Web of Science, Google scholar, and NGO websites for articles published between 2010 and April 2020. We synthesized the involvement of KP community members or lay providers in medical task provision, and outcomes along the continuum of HIV care. Of 3,330 records identified, 66 were eligible for full test screening, out of which 12 were included in the review. CBART for KP was provided through: (a) community drop-in-centres, (b) community drop-in-centres plus mobile team, or (c) community-based health centres. KP were engaged as peer educators and they provided services such as community mobilisation activities for HIV testing and ART, ART adherence counselling, and referral for ART initiation. Across the KP-CBART studies, outcomes in terms of ART uptake, adherence to ART, retention in care and viral suppression were at least as good as those obtained for KP attending facilitybased care. KP-CBART was as effective as facility-based care. To achieve the UNAIDS 95-95-95 target in sub-Saharan Africa, national programmes should scale-up KP-CBART to complement facility-based care.
\end{abstract}

Keywords Key population $\cdot$ Female sex workers $\cdot$ Community-based antiretroviral therapy $\cdot$ HIV

\section{Introduction}

Key populations (KP) include female sex workers (FSW), men who have sex with men (MSM), transgender people (TG), persons who inject drugs (PWID), and people in prisons and other closed settings [1]. The risk of HIV acquisition among MSM, PWID, sex workers and TG are respectively 22, 22, 21 and 12 times higher than for adults aged 15-49 years [2]. The HIV prevalence among KP varies

Olujuwon Ibiloye

juonib26@gmail.com

Institute of Tropical Medicine, Antwerp, Belgium

APIN Public Health Initiatives, Abuja, Nigeria

Research Foundation Flanders, 1000 Brussels, Belgium

University of Antwerp, Antwerp, Belgium widely across regions and countries in sub-Saharan African. In 2018, Uganda had the highest HIV prevalence of $85 \%$ among FSW while Sudan had the lowest $(0.7 \%)$ of the continent [3]. In East and Southern Africa, an estimated 54\% of sex workers are living with HIV [4]. The HIV prevalence among MSM ranges between $1.2 \%$ in Sudan (2018) and $32.9 \%$ in Lesotho (2014) [3].

In 2018, KP and their sexual partners accounted for more than fifty percent of all new HIV cases in Sub-Saharan Africa (SSA). In West and Central Africa, KP, their clients and sexual partners accounted for $64 \%$ of new infections and for $25 \%$ of new HIV infections in East and Southern Africa $[4,5]$. Therefore, improving service coverage for KP could avert a significant number of new infections, stabilise and reverse the HIV incidence rates [1]. KP are often stigmatised and discriminated against, which impacts negatively on access to quality HIV care in regular health care facilities. Other factors limiting access of KP to HIV care, including 
access to antiretroviral treatment (ART), in SSA include: lack of community support, harassment by law enforcement agencies, laws and policies restricting access, criminalization of behaviours or practices and violence [6]. To improve access to community-based antiretroviral therapy service delivery (CBART) models that bring HIV care and treatment closer to the KP community and encourage participation of KP (communities) in HIV service delivery have been advocated for [7]. Also the World Health Organization has recommended decentralization of ART initiation and/or refill and community-based HIV approaches (such as outreach sites, mobile services, home-based services or communitybased organizations) to overcome barriers to HIV care [1].

Community-based approaches to HIV care and treatment have proven to be an effective method of reaching people in the general population, particularly for individuals who are hard to reach [8]. These approaches include communitybased and venue-based outreach activities, community-based ART initiation and refill, and home-based ART [1,9]. If adapted to the needs of KP, such programs may also engage KP communities in HIV service delivery. Indeed, participation of PLHIV in chronic lifelong care has been identified as an enabler of service utilisation and adherence to treatment [10]. The CBART model for KP (KP-CBART) is a clientcentred approach to ART services that aims to increase utilisation of services and retention in care by organising ART delivery closer to the patients' home and at the same time strengthen social networks of HIV-positive KP [11].

A recently published review showed the effect of community-based HIV care along the HIV care continuum among FSW. The HIV care continuum "is a public health model that outlines the steps or stages that people with HIV go through from diagnosis to achieving and maintaining viral suppression (a very low or undetectable amount of HIV in the body" [12]. However, this review only focussed on FSW, included studies regardless of the level of involvement of FSW in care provision, and included studies regardless of whether ART was provided within the communities. Moreover, the modalities used for KP-CBART were not summarized [13]. In our review, we explored the effect of CBART along the continuum of HIV care on clinical outcomes among KP in sub-Saharan Africa. We collected data on community-based HIV care for any type of KP, and only included studies if $\mathrm{KP}$ were involved in care delivery along the HIV care continuum, and if care delivery also included ART.

We described the KP-CBART model used, including the type of services provided and the type of KP among beneficiaries, the roles of KP and other key stakeholders in HIV service delivery, and the outcomes of KP-CBART interventions along the continuum of HIV care and treatment (uptake of HIV testing services, linkage to ART, retention, and viral suppression). We also summarized the predictors of retention among KP receiving care in KP -CBART models.

\section{Methods}

This is a scoping review of the evidence on the effect of community-based ART service delivery on clinical outcomes along the continuum of HIV care for KP in SSA countries. Outcomes along the continuum of HIV care include HIV testing uptake, diagnosis of an HIV infection, linkage to care, medication adherence, and ART outcomes (viral suppression and retention [or the opposite, attrition, including those who died or were lost to follow-up (LTFU)]. The framework was developed as recommended by Arksey and O'Malley [14]. This framework helps to clarify when a scoping study is the appropriate method to adopt for evidence synthesis and how to go about the review [14]. The methodology used in this review is coherent with the Preferred Reporting Items for Systematic reviews and extension for Scoping Reviews (PRISMA-ScR) [15].

\section{Eligibility Criteria}

Articles were included in the review if they:

(a) presented data on community-based (delivered from a community venue) or community-led (involvement of KP community members or lay providers in medical HIV service provision) ART delivery programme for KP (FSW, MSM, PWID and/or TG) in Sub-Saharan Africa, and

(b) reported data on one or more ART outcomes.

Papers published before 2010 were not considered, as community-based approaches to HIV care and ART delivery became popular after this time [16]. Only articles that were written and published in English were included.

\section{Information Sources}

We searched and extracted articles between April 2020 and May 2020 from the Medline database (through Pubmed). Web of Science was searched in September 2021. The grey literature (Google Scholar) and Websites of World Health Organization (WHO), International AIDS Society (IAS) and other international HIV agencies ( non-governmental organizations) were also searched. Finally, reference lists of retrieved studies were searched.

\section{Search}

Two researchers (IO and TD) conducted the literature review. The search string was constructed using the PICO approach (Table 1). Terms were entered as Medical subheading terms $(\mathrm{MeSH})$ or free text string as shown in Table 1. 
Table 1 Search strategy using the PICO approach

\begin{tabular}{|c|c|c|}
\hline \multicolumn{2}{|l|}{ Sources } & \multirow{2}{*}{$\begin{array}{l}\text { Search string for Pubmed } \\
\text { ("sex workers" [MeSH] or "FSW" or "MSM" or "men who have } \\
\text { sex with men" or "transgenders" or "persons who inject drugs" or } \\
\text { "PWID" or "IVDU") AND "Africa" }\end{array}$} \\
\hline Medline (Pubmed), Web of Science*, \& Google Scholar & Population & \\
\hline \multirow[t]{2}{*}{ Websites of KP organizations } & Intervention & $\begin{array}{l}\text { "Community" or "peer"[All field] or "home") AND ("HIV" [MeSH]" } \\
\text { or "antiretroviral therapy" or "ART" or "HAART") }\end{array}$ \\
\hline & Comparison & Not applicable \\
\hline Reference list of retrieved citations & Outcomes & $\begin{array}{l}\text { "linkage" or "retention" or "attrition" or "viral suppression" or "treat- } \\
\text { ment outcome" }[\mathrm{MeSH}]\end{array}$ \\
\hline
\end{tabular}

*Search string for Web of Science is in Supplementary Table 2

\section{Selection of Sources of Evidence}

After conducting the search, duplicates were identified and removed using Mendeley reference software. Thereafter, titles and abstracts of retrieved studies were screened. Only studies that presented original data on the topic of interest were retrieved. Then the full text of retrieved studies was read and the inclusion criteria were applied.

\section{Data Charting Process}

Extracted data were encoded in a data collection tool (Excel sheet), conceived and tested before the start of the review (see the attached Supplementary File 1 for the data extraction template).

\section{Data Collection and Synthesis}

We collected thematic data on KP-CBART delivery, such as type of CBART model, intervention components, characteristics of lay providers (including KP) and their roles, and capacity building (training) of care providers.

We collected quantitative data on the study title, author, publication year, study period, study location, study design, study setting, sample size, participant characteristics (e.g. HIV status, KP type), and continuum of HIV care outcomes. Outcomes included uptake of HIV testing, HIV testing positivity among those tested, linkage to HIV care among those tested positive, ART uptake among those linked to care, medication adherence, clinical outcomes among those on ART, including retention (or the opposite: attrition, which usually was defined as the sum of deaths and those LTFU), and viral suppression. We also collected data on the definitions used for these outcomes. Finally, data were collected on factors associated with retention or attrition, as reported in the studies. The collected data were summarized in Tables 2, 3, 4, 5, 6, 7 and 8).

\section{Results}

The selection of articles is shown in Fig. 1. The database search identified 3330 published articles in Pubmed (3033) and Web of Science (297). Additional search on Google scholar did not result in papers not yet retrieved from Pubmed. One paper was identified on a non-governmental organizations' website. From the reference lists of relevant articles we retrieved five additional papers. The titles and abstracts of identified papers were screened to remove duplicates and to exclude papers that did not show original data or did not provide data on community-based service delivery for key populations (See prisma). The full text of the remaining 66 selected articles was read. After applying the inclusion criteria, 11 articles and 1 report were included in the review.

The twelve papers described CBART programs for KP in 6 sub-Saharan African countries. The study characteristics are summarized in Table 2. Three of the studies were randomised controlled trials (RCT) [17-19]. One RCT enrolled FSW and was randomised at the community level [17] and the other two randomized at the level of care delivery sites studied FSW [18] and MSM [19]. The other nine studies were observational studies, including five prospective studies, two retrospective studies, one report showing a retrospective data analysis, and a survey [20-28]. Six observational studies targeted FSW. One observational study [22] and one report on multi-country community-based HIV program in Ivory Coast, Malawi, South Sudan and Democratic Republic of Congo (DRC) targeted both MSM and FSW [24]. Three observational studies were designed for MSM only [25-27].

\section{Thematic Data on KP-CBART Delivery}

\section{Community-Based ART (CBART) Models}

ART services were provided to KP through either a community Drop-in-Centre (DIC), a community DIC with a mobile team, or a community-based health facility (Tables 2 and 


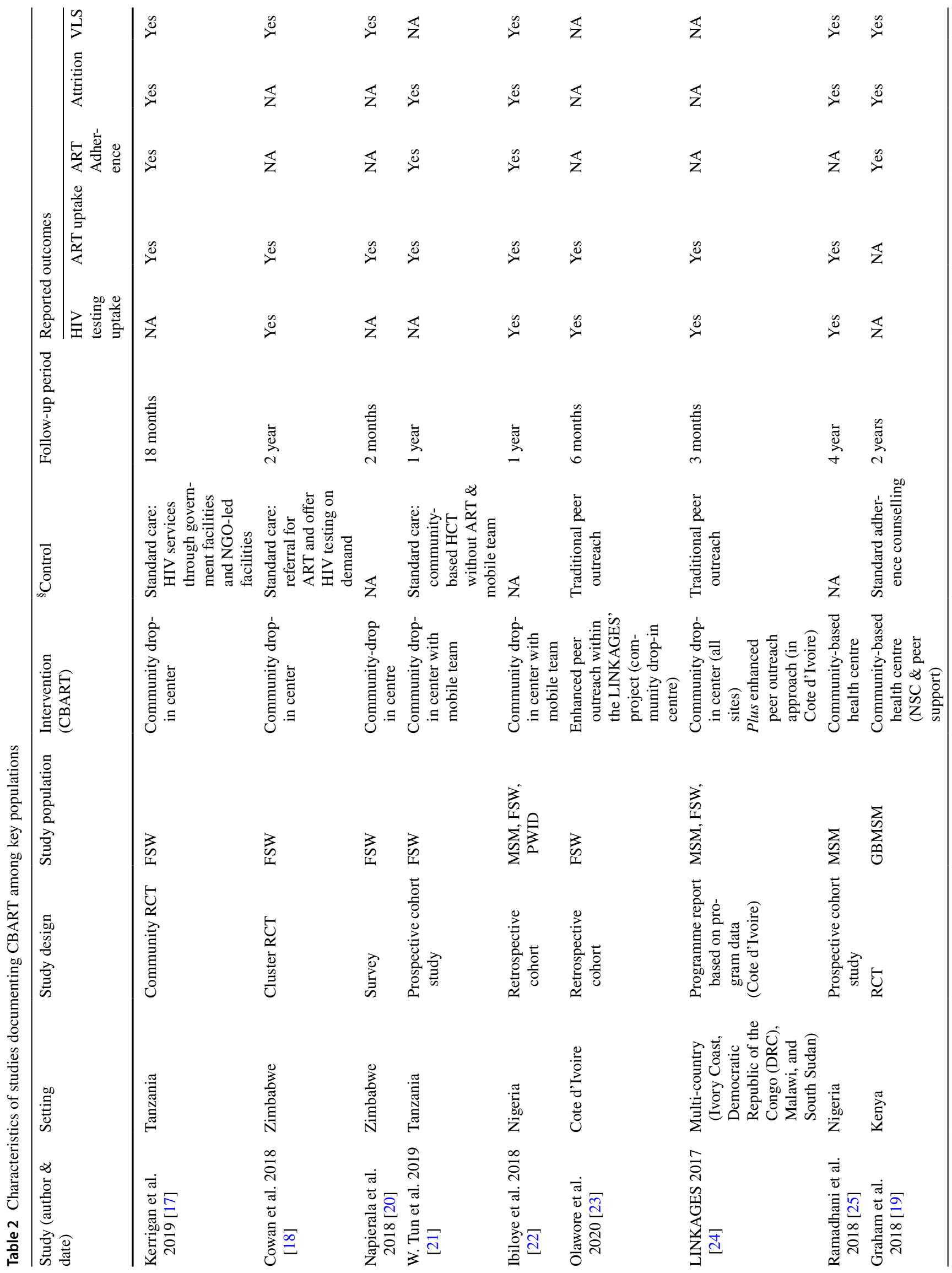




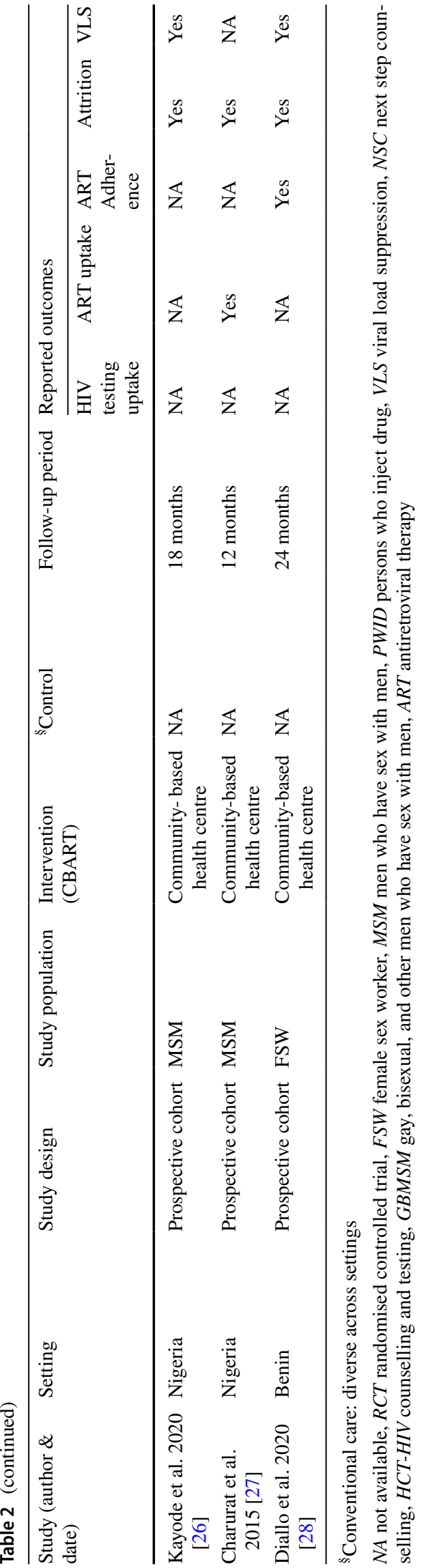

3). One site also offered enhanced peer outreach next to a DIC. What differentiates these models from each other are the locations of service delivery, the roles of care providers in ART delivery, and the package of HIV services offered to KP.

A DIC aims at being safe for members of KP to meet, make friends and develop a sense of community [24]. To enhance accessibility and acceptability for KP, DIC were located in close proximity to the hotspots (a location in the community where members of KP gather or meet) and were run by KP themselves. Operation hours at the DIC were convenient. DIC served as venues for meeting, social gathering and clinical activities [24]. A comprehensive package of services, such as HIV testing and counselling, condom distribution, ART initiation, referral for ART, and etc., were carried out by clinicians and lay health workers or peer educators in these centres. The DIC were linked to either a communitybased ART centre or primary health centre (PHC) for technical support on all aspects of ART provision [17, 18, 24].

A DIC with outreach through a mobile team provides, in addition to DIC activities, a mobile health team comprising of clinicians, nurses and peer educators conducting ART outreach to venues of clients' preference (the patient's home, brothels, and PHC) for HIV testing, ART enrolment and initiation on specific days [21, 22, 24]. Home-based ART services were provided by the mobile health team in Tanzanian study [21]. Four studies, conducted in Tanzania, Zimbabwe and Nigeria, implemented DIC and mobile ART or outreaches for HIV testing services and/or ART initiation or refill [21-24]. In two studies, a mobile health team, comprising of clinicians, nurses and peer educators, were engaged to provide ART services through community-based HIV testing and counselling (CBHTC) and ART [21, 22]. Only one study offered home-based ART initiation [21]. The Nasarawa state study in Nigeria implemented a DIC and mobile ART outreach for MSM, FSW and PWID [22]. In the LINKAGE program, enhanced peer-led outreach was implemented for MSM and FSW in Ivory Coast. This strategy involved one-on-one meetings with KP to provide condoms and lubricants, information and education activities on HIV, and referral of peers for HIV testing and ART initiation. This enhanced peer outreach approach included intensive and targeted community-based activities aiming at improving HIV testing uptake and linkage to ART services [23, 24].

Six studies reported using community-based health centre strategy in delivering ART services to either FSW or MSM [19, 25-28]. These centres were dedicated to either MSM or FSW and were established by research institutions or NGOs to provide comprehensive HIV and STI services. Health care professionals (mostly clinicians) provided HIV care and treatment services to clients in these centres. Services provided in these centres included condom distribution, ART initiation, viral load testing, etc. Members of KP (such as 


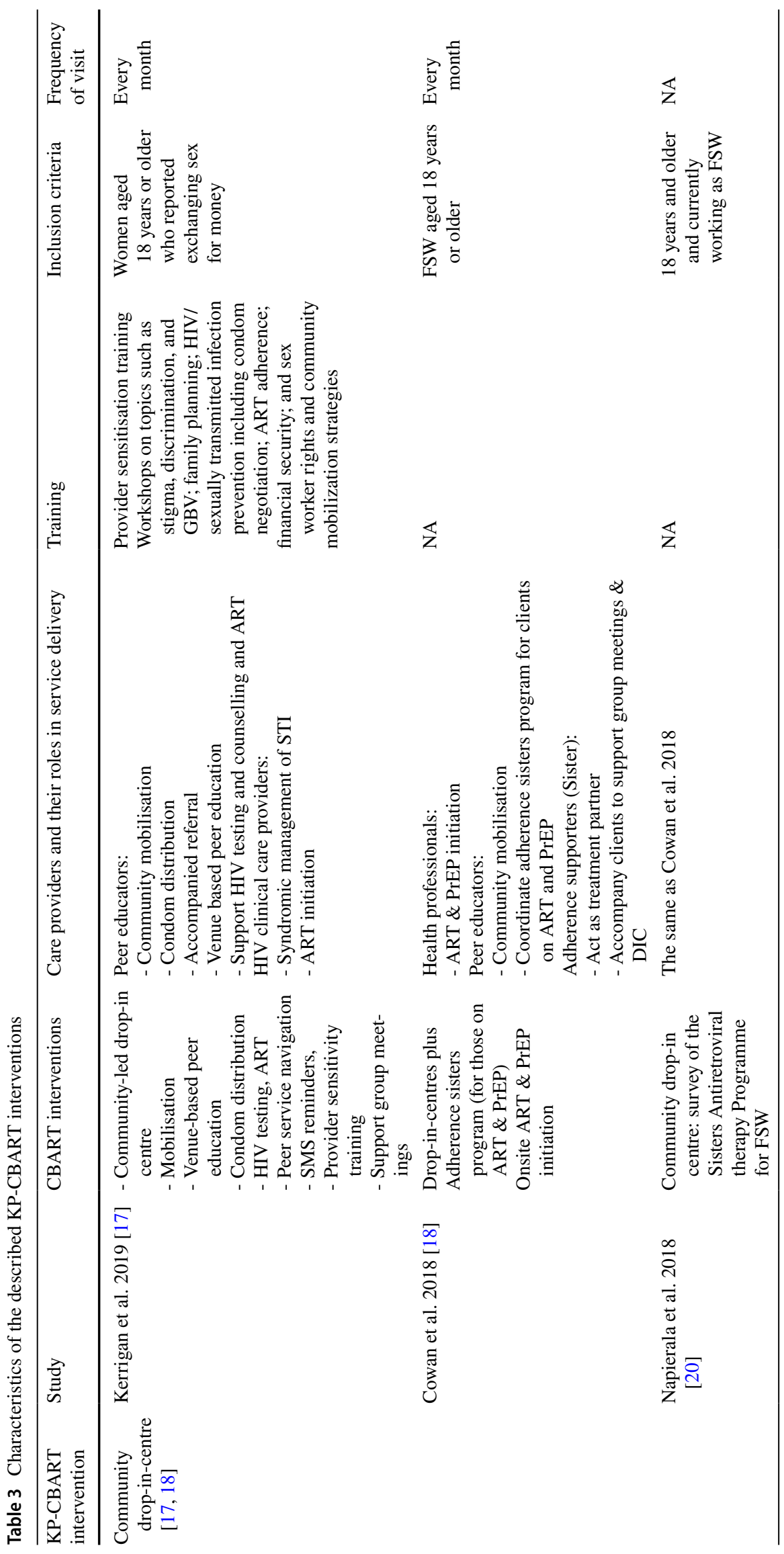




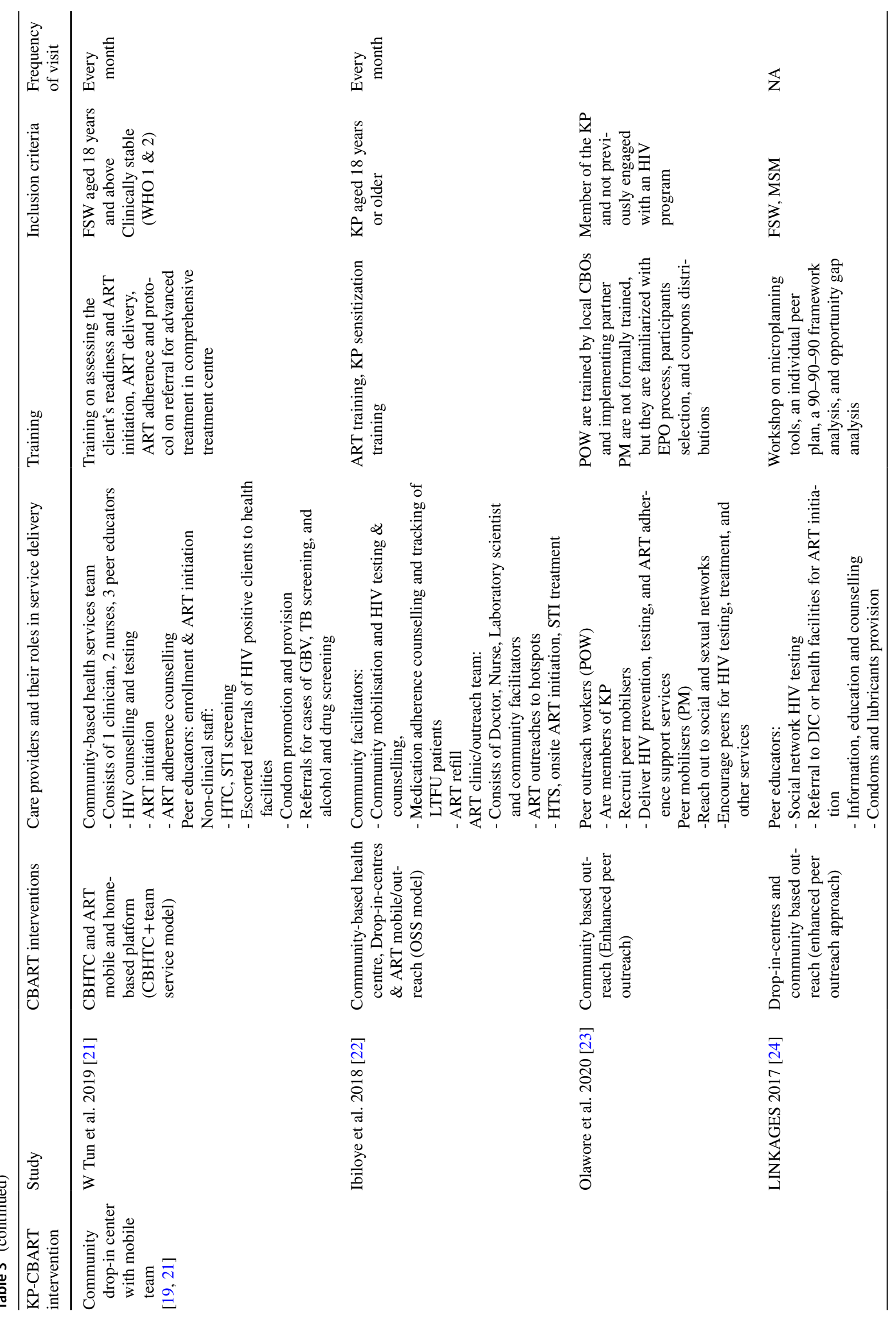




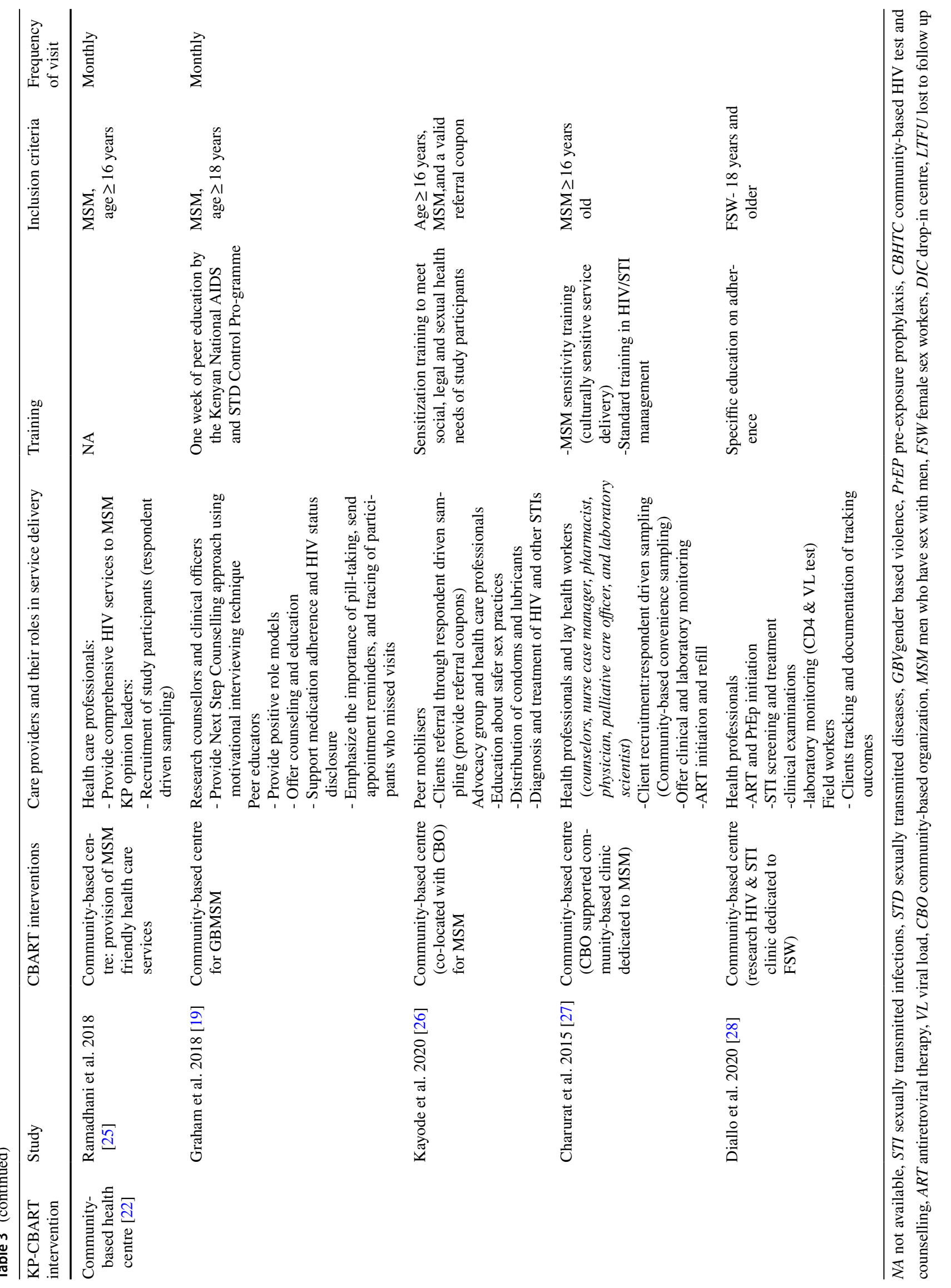




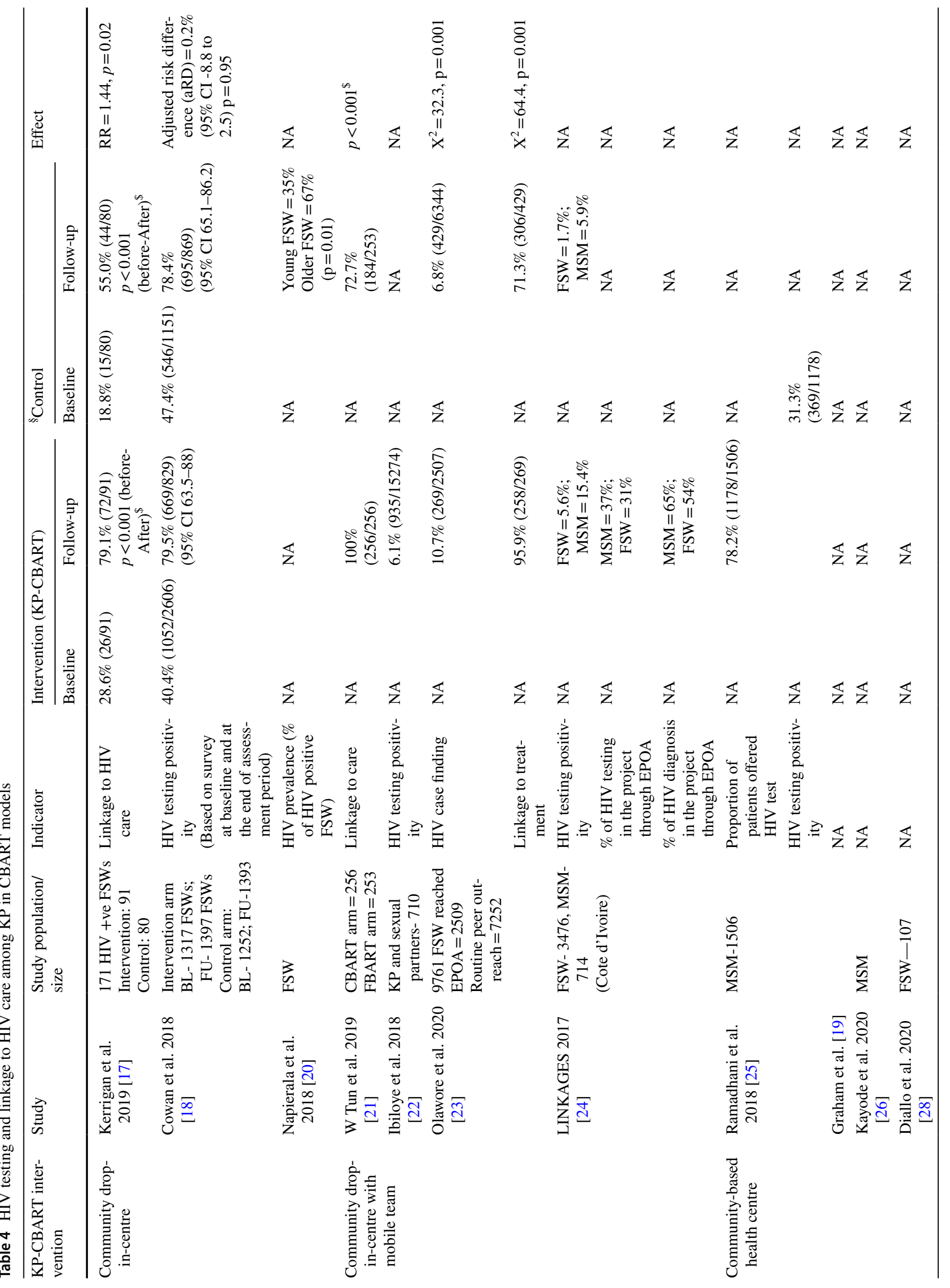


key opinion leaders) and health care professionals together managed and coordinated activities in these communitybased health centres. Four studies reported on findings from community-based health centres for MSM [19, 25-27] and one paper described care provided at a community-based health centre for FSW [28]. Community-based health centres were implemented in Kenya and Nigeria, where lay workers and KP peers supported and health care professionals provided ART care to HIV positive MSM [19, 26, 27]. One study described outcomes from a community-based health centre for FSWs in Cotonou, Benin [28].

\section{Roles of KP Communities in CBART Service Delivery}

All the community-based ART programs included in this review engaged KP or lay health workers to provide HIV care and/or ART (Table 3). They were involved in ART care to ensure sustainability and programme ownership by members of KP, and improve their access to quality HIV services.

\section{Community Mobilisation (Peer Education and Navigation)}

In all the KP-CBART programmes described in this review, FSW and MSM were involved as peer educators or mobilisers. They actively mobilised their peers and KP communities for HIV testing, linkage to HIV care, ART initiation and viral load testing. Services offered by trained peer educators include venue-based peer education, condom distribution, ART referral with or without assistance (escort services) and clients tracking for ART refill.

\section{ART Service Delivery (ART Initiation, ART Refill, ART Adherence and Tracing of LTFU)}

Members of the KP community, trained as peer educators, supported ART delivery in the community, through DIC, outreach venues (including home-based venues), and community-based health facilities. Eleven studies documented KP roles in antiretroviral therapy delivery, they offered ART referral to HIV positive patients and medication adherence counselling to those on ART [17-19, 21-27]. Furthermore, peer educators and navigators tracked patients who were LTFU in the project, either through SMS, phone calls or physical contact to improve retention in care.

In the DIC and mobile health team model in Tanzania, peer educators were reported to have initiated HIV-positive FSW on ART [21].

\section{Training}

In the Tanzania study, the KP-CBART delivery programme was designed in line with the national ART guidelines and the national community-based HIV and AIDS services 
Table 5 Uptake of ART among KP in CBART models

\begin{tabular}{|c|c|c|c|c|c|c|c|c|}
\hline \multirow{2}{*}{$\begin{array}{l}\text { KP-CBART } \\
\text { model }\end{array}$} & \multirow[t]{2}{*}{ Study } & \multirow{2}{*}{$\begin{array}{l}\text { Study popula- } \\
\text { tion/size }\end{array}$} & \multirow[t]{2}{*}{ Indicator } & \multicolumn{2}{|c|}{ Intervention (CBART) } & \multicolumn{2}{|l|}{${ }^{\S}$ Control } & \multirow[t]{2}{*}{ Effect } \\
\hline & & & & Baseline & Follow-up & Baseline & Follow-up & \\
\hline \multirow[t]{3}{*}{$\begin{array}{l}\text { Community } \\
\text { drop-in- } \\
\text { centre }\end{array}$} & $\begin{array}{l}\text { Kerrigan et al. } \\
2019 \text { [17] }\end{array}$ & $\begin{array}{l}171 \mathrm{HIV}+\mathrm{ve} \\
\text { FSWs } \\
\text { Intervention: } \\
91 \\
\text { Control: } 80\end{array}$ & Ever on ART & $28.0 \%(26 / 91)$ & $\begin{array}{l}82.4 \%(75 / 91) \\
p<0.001 \\
\text { (before- } \\
\text { After) }^{\$}\end{array}$ & $18.8 \%(15 / 80)$ & $\begin{array}{c}67.5 \%(54 / 80) \\
p<0.001 \\
\quad \text { (before- }^{\$} \\
\text { After) }^{\$}\end{array}$ & $\begin{array}{c}\mathrm{RR}=1.22 \\
p=0.03\end{array}$ \\
\hline & $\begin{array}{c}\text { Cowan et al. } \\
2018 \text { [18] }\end{array}$ & $\begin{array}{l}\text { Intervention } \\
\text { arm } \\
\text { BL- } 1317 \\
\text { FSWs; FU- } \\
\text { 1397 FSWs } \\
\text { Control arm: } \\
\text { BL- 1252; } \\
\text { FU-1393 }\end{array}$ & $\begin{array}{l}\text { Reported } \\
\text { being HIV } \\
\text { positive and } \\
\text { taking ART }\end{array}$ & NA & $\begin{array}{l}86.3 \% \\
(95 \% \text { CI } \\
78.7-96.0) \\
594 / 669\end{array}$ & NA & $\begin{array}{l}83.0 \% \\
(95 \% \mathrm{CI} \\
72.4-89.8) \\
580 / 695\end{array}$ & $\begin{array}{c}\mathrm{aRD}=3.4 \% \\
(-2.9 \text { to } 9.7) \\
\mathrm{p}=0.22\end{array}$ \\
\hline & $\begin{array}{l}\text { Napierala } \\
\text { et al. } 2018 \\
\text { [20], }\end{array}$ & FSW & ART uptake & NA & NA & NA & $\begin{array}{c}<25 \text { years } \\
\text { old }=55 \% \\
=/>25 \text { years } \\
\text { old }=68 \% \\
(p=0.06)^{\$}\end{array}$ & NA \\
\hline \multirow[t]{4}{*}{$\begin{array}{l}\text { Community } \\
\text { drop-in- } \\
\text { centre and } \\
\text { mobile team }\end{array}$} & $\begin{array}{l}\text { W. Tun et al. } \\
2019 \text { [21] }\end{array}$ & $\begin{array}{l}\text { CBART } \\
\text { arm }=256 \\
\text { FBART } \\
\text { arm }=253\end{array}$ & $\begin{array}{l}\text { Initiated on } \\
\text { ART }\end{array}$ & NA & $\begin{array}{l}100 \% \\
(256 / 256)\end{array}$ & NA & $\begin{array}{l}71.5 \% \\
(181 / 253)\end{array}$ & $p=0.04^{\$}$ \\
\hline & $\begin{array}{c}\text { Ibiloye et al. } \\
2018 \text { [22] }\end{array}$ & $\begin{array}{l}\text { KP and sexual } \\
\text { partners- } \\
710\end{array}$ & $\begin{array}{l}\text { Initiated on } \\
\text { ART }\end{array}$ & NA & $\begin{array}{l}77.4 \% \\
(724 / 935)\end{array}$ & NA & NA & NA \\
\hline & $\begin{array}{l}\text { Olawore et al. } \\
2020 \text { [23] }\end{array}$ & FSW & ART initiation & NA & $\begin{array}{l}78.8 \% \\
\quad(212 / 269)\end{array}$ & NA & $\begin{array}{l}73.3 \% \\
(315 / 429)\end{array}$ & $\begin{aligned} X^{2} & =2.6 \\
p & =0.11\end{aligned}$ \\
\hline & $\begin{array}{c}\text { LINKAGES } \\
2017 \text { [24] }\end{array}$ & $\begin{array}{l}\text { FSW- } 3476, \\
\text { MSM-714 } \\
\text { (Cote d'Ivoire) }\end{array}$ & $\begin{array}{l}\text { Initiated on } \\
\text { ART (\% } \\
\text { contribution } \\
\text { of EPOA to } \\
\text { overall pro- } \\
\text { ject result) }\end{array}$ & NA & $\begin{array}{l}\mathrm{MSM}=83 \% \\
\mathrm{FSW}=54 \%\end{array}$ & NA & NA & NA \\
\hline \multirow[t]{5}{*}{$\begin{array}{l}\text { Community- } \\
\text { based health } \\
\text { centre }\end{array}$} & $\begin{array}{l}\text { Ramadhani } \\
\text { et al. } 2018 \\
\text { [25] }\end{array}$ & MSM-1506 & $\begin{array}{l}\% \text { of HIV } \\
\text { positive } \\
\text { patients } \\
\text { initiated on } \\
\text { ART }\end{array}$ & NA & $\begin{array}{l}50.1 \% \\
(188 / 369)\end{array}$ & NA & NA & NA \\
\hline & $\begin{array}{c}\text { Graham et al. } \\
2018 \text { [19] }\end{array}$ & GBMSM & NA & NA & NA & NA & NA & NA \\
\hline & $\begin{array}{c}\text { Kayode et al. } \\
2020 \text { [26] }\end{array}$ & MSM & ART initiation & NA & NA & NA & NA & NA \\
\hline & $\begin{array}{c}\text { Charurat et al. } \\
2015 \text { [27] }\end{array}$ & MSM- 706 & ART initiation & NA & NA & NA & $\begin{array}{l}54.7 \% \\
(70 / 128)\end{array}$ & NA \\
\hline & $\begin{array}{r}\text { Diallo et al. } \\
2020 \text { [28] }\end{array}$ & FSW- 111 & ART Initiation & NA & NA & NA & $\begin{array}{l}96.3 \% \\
(107 / 111)\end{array}$ & NA \\
\hline
\end{tabular}

${ }^{\$}$ The original study reported a p-value without a value for the statistical test

${ }^{\S}$ Conventional care: diverse across settings

$E P O A$ enhanced peer outreach approach, $B L$ baseline, $F U$ follow up or end of assessment period, $a R D$ adjusted risk difference, $F B A R T$ facilitybased ART, $C B A R T$ community based ART

guidelines [21]. Trainings that were conducted prior and during implementation included assessment of clients' readiness and ART initiation, ART delivery, ART adherence and use of protocol on referral for advanced treatment in comprehensive treatment centres (Table 3). Meanwhile, in the MSM study in Nigeria, care providers received standard training on provision of culturally competent services (provider sensitivity training) and management of HIV/ 


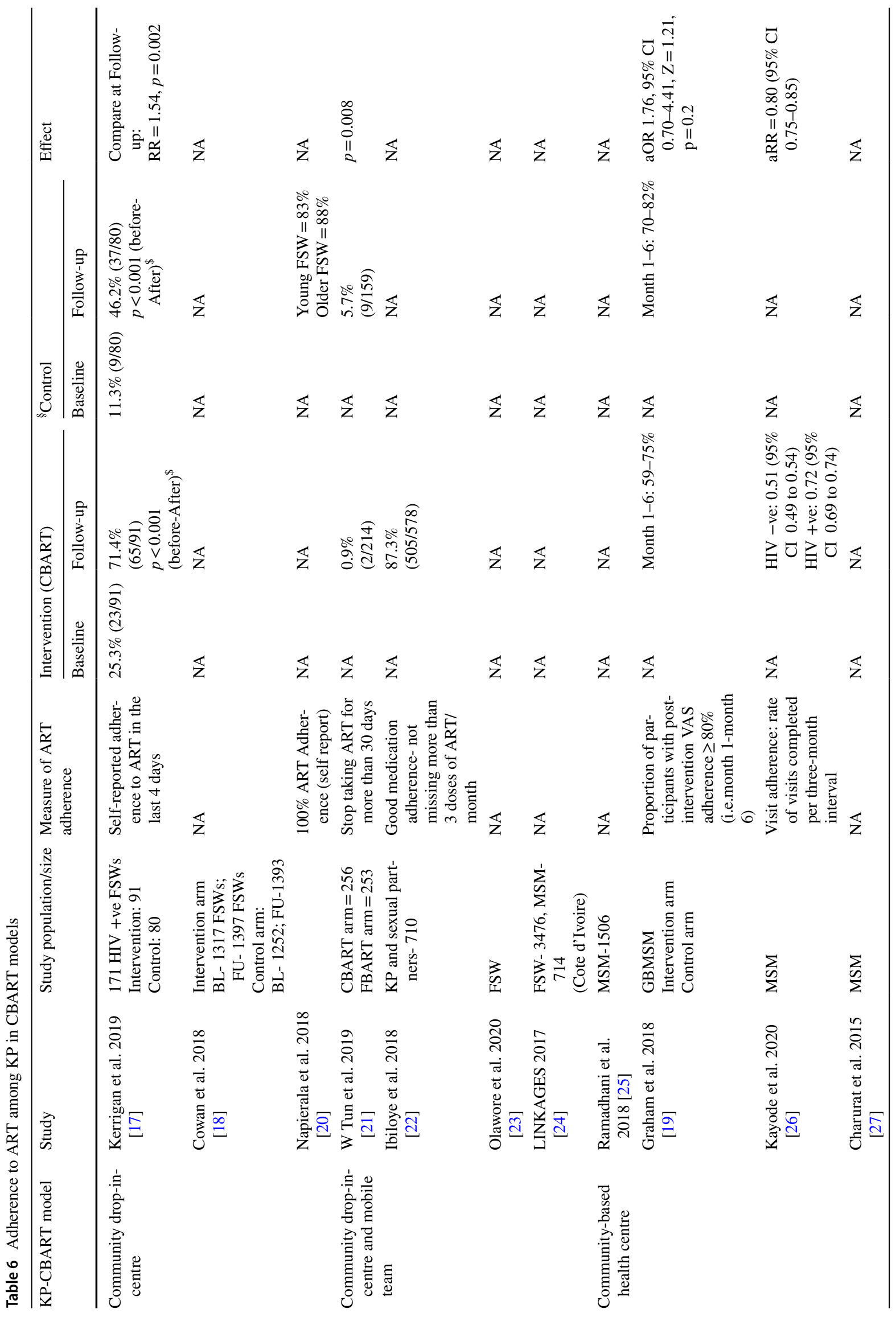




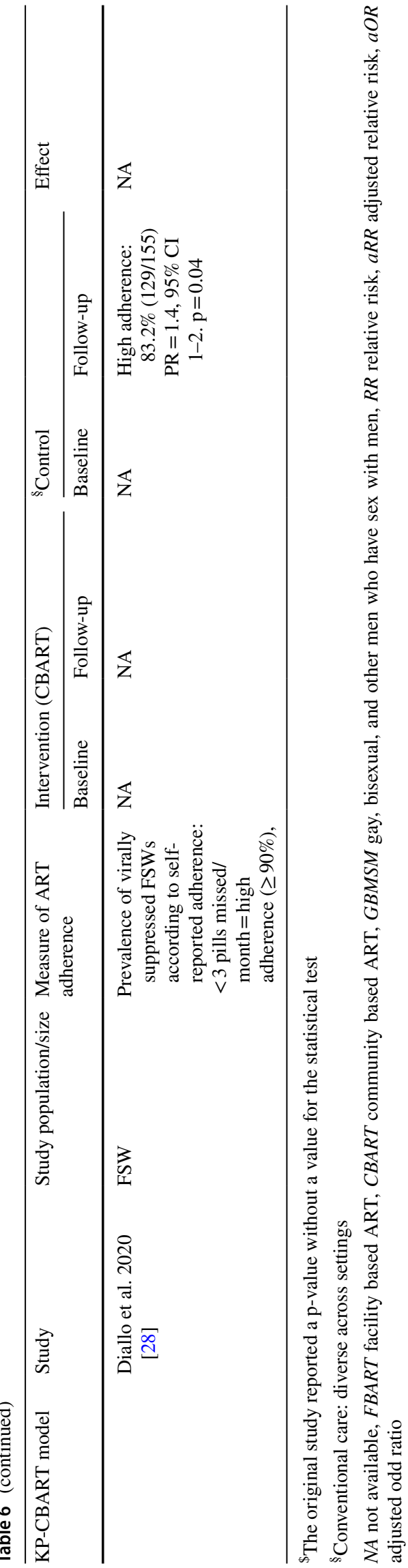

STD diagnosis [25, 26]. Furthermore, additional trainings and workshops organized for KP community workers and care providers included topics on community mobilisation strategies, HIV/STI prevention (condom negotiation, ART adherence), family planning, gender based violence (GBV), financial security, police sensitivity training and sex worker rights [17].

Moreover, trained KP offered psychological and social support through their leadership and membership in support groups such as Shikamana support group, Savings and Violence support groups, Adherence Sisters program in Tanzania and Zimbabwe [17, 18]. These support groups were coordinated by programme staff, peer educators and other key stakeholders.

KP were also involved in HIV programme planning, implementation and evaluation. In Tanzania, FSWs were members of the Community Advisory Board that offered guidance on KP-programme implementation in the studyregion [17].

\section{Quantitative Data on KP-CBART Outcomes}

\section{HIV Testing Uptake}

Across all studies, KP were tested, diagnosed with HIV and linked to HIV care (Table 4). HIV testing was strategic and targeted, therefore yielding high number of HIV positive results in the studies from Nigeria, Cote d'Ivoire, and Tanzania $[17,22,24,25]$. One of the studies reported a lower rate HIV positive results in the community-based intervention arm compared to the control [17].

\section{ART Uptake}

Three articles compared a CBART intervention with a control arm for ART initiation among KP. In two studies conducted in the Tanzania and Zimbabwe, CBART was significantly associated with a higher likelihood of ART initiation. For one study the correlation was not significant (Table 4) [18]. Overall, between 54.7 and 100\% of KP who tested HIV positive were initiated on ART in the community-based settings. Factors found to be associated with high ART uptake were a high level of education and having a strong social network [18].

\section{Retention in Care}

The definition of retention among those started on ART varied across programmes and depending on the study, retention in care was assessed at different timepoints (Table 8). Retention in care was operationalized in different ways across the included studies i.e. current on ART, completed 6 months of ART, and default on ART appointment of less 


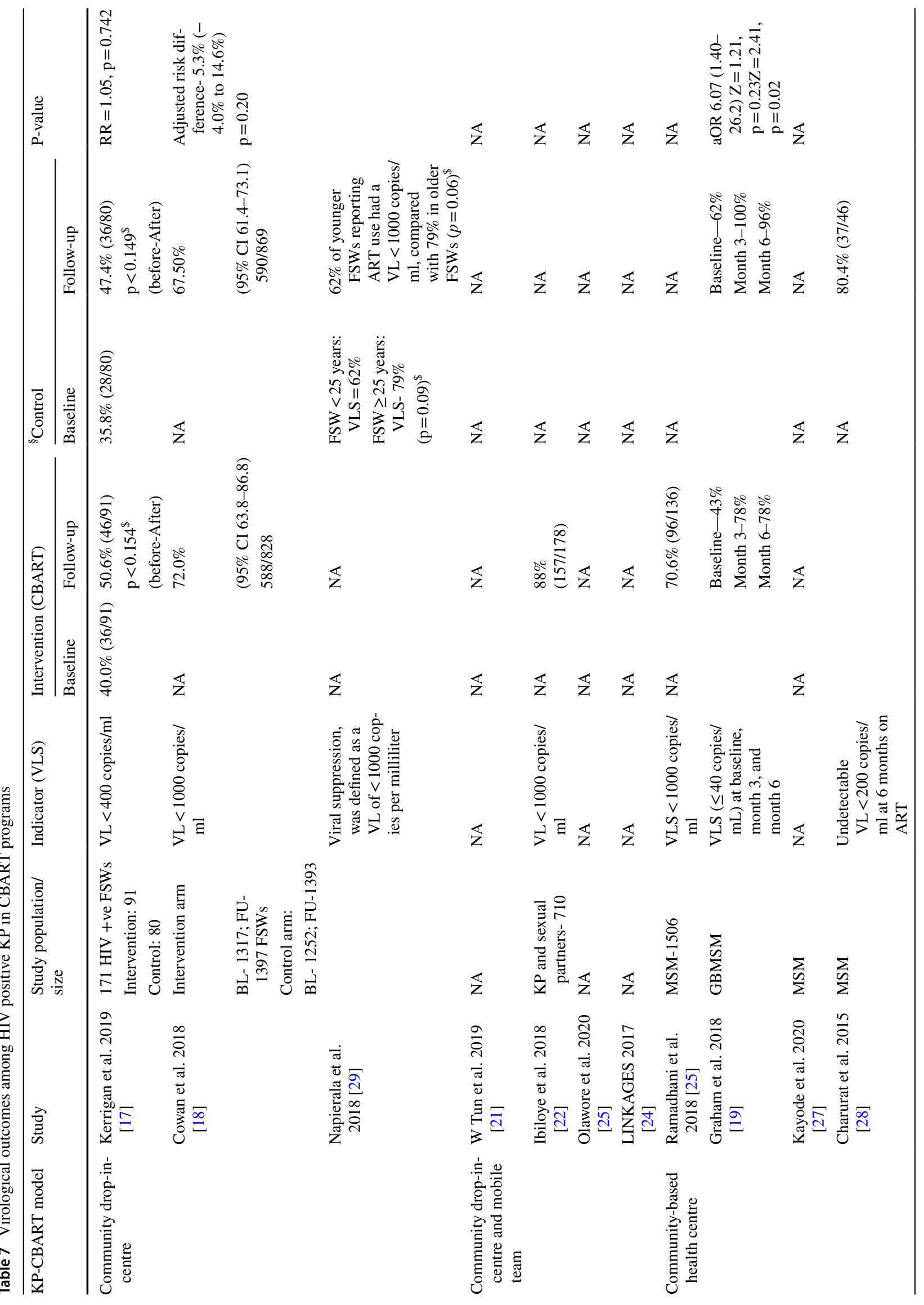




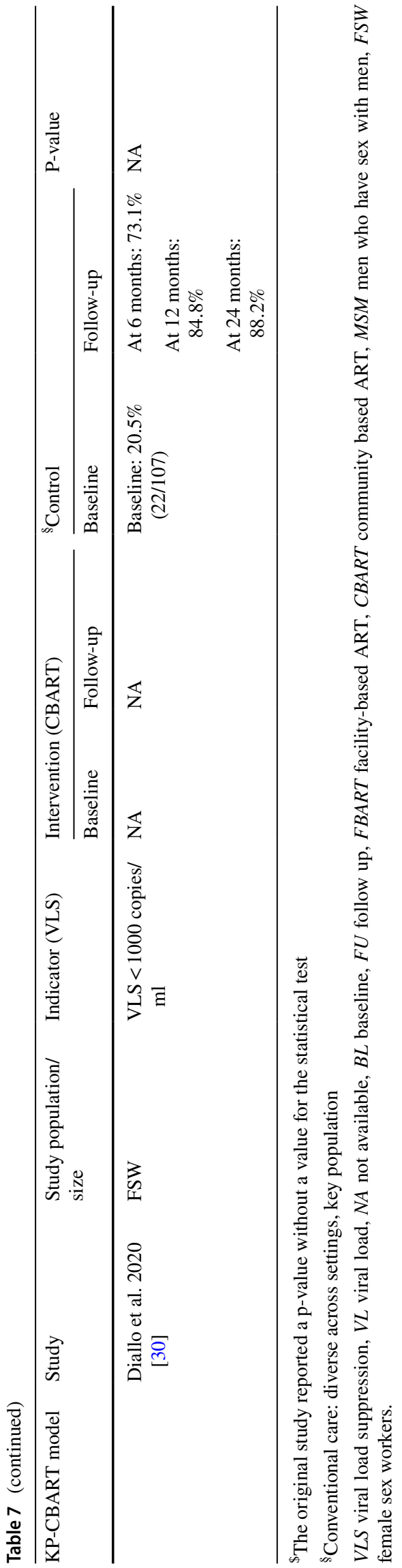

than 2 months. The RCT study in Zimbabwe compared retention on ART (proportion of patients who are active on ART at 18 months) between those in a control arm and those in a CBART arm. Retention was significantly higher in the CBART arm $(81.3 \%$ vs. $63.8 \%$; $=0.013)$ [17]. The Tanzania's RCT and MSM study in Nigeria did not report retention outcomes. Retention in the intervention arms of the RCTs and prospective cohort studies was higher than $80 \%$ [17-19, 21]. One study compared the proportion on ART among all those who tested HIV positive, and did not find a difference between the control and the CBART arm (83.0\% vs $86.3 \%, p=0.22$ ) [18]. Factors reported to be associated with attrition included low level of education, unemployment, stigma and lack of social network or support (Table 8). Other reasons for LTFU includes high mobility of sex workers when changing work environment and seeking clients in other cities or countries [28]. In the community-based HIV test and counselling (CBHTC) mobile and home-based ART study in Tanzania, there was no statistically significant difference for patient characteristics between those LTFU and those retained in care in the intervention arm (KP-CBART). However, in the control arm (facility-based care), clients who were LTFU, were younger and less likely to go to other regions for sex work in the 6 months before study assessment [18].

\section{Viral Suppression}

Eight papers reported on viral load suppression (VLS) (Table 7). KP who received ART in the community-based interventions achieved non-significantly higher VLS rate compared to the control arm $[17,18,21]$ except in the Kenya study that reported sixfold higher odds of viral suppression (OR 6.24, 95\% CI 1.28-30.5, $\mathrm{Z}=2.26, \mathrm{p}=0.02$ ) among gay, bisexual, and men who have sex with men (GBMSM) [19]. One of the studies found that having astronger supportive social network increased the odds of viral suppression [21].

\section{Discussion}

Findings from this scoping review on the effect of KPCBART on outcomes along the HIV care continuum ranging from HIV testing to viral load suppression and retention in care including ART delivery, showed that outcomes in KP-CBART were at least as good as in facility-based care. Our conclusion is coherent with the conclusion from a recent review on CBART for FSW, even though most of the included studies did not overlap, as different inclusion criteria were used [13]. Our review only included studies for which ART delivery was part of the intervention, and studies in which KP had a role in KP-CBART delivery. We used these criteria as community-based HIV services without 


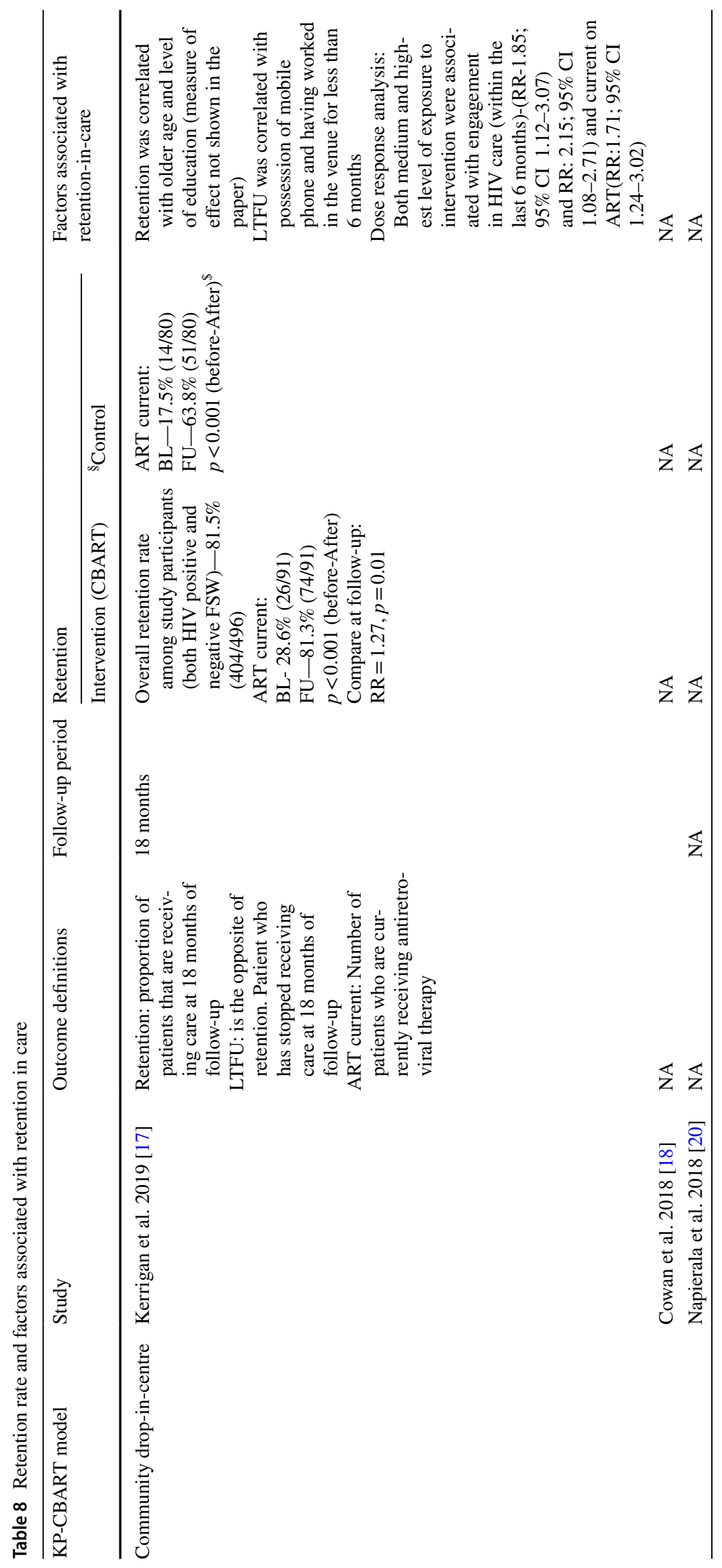




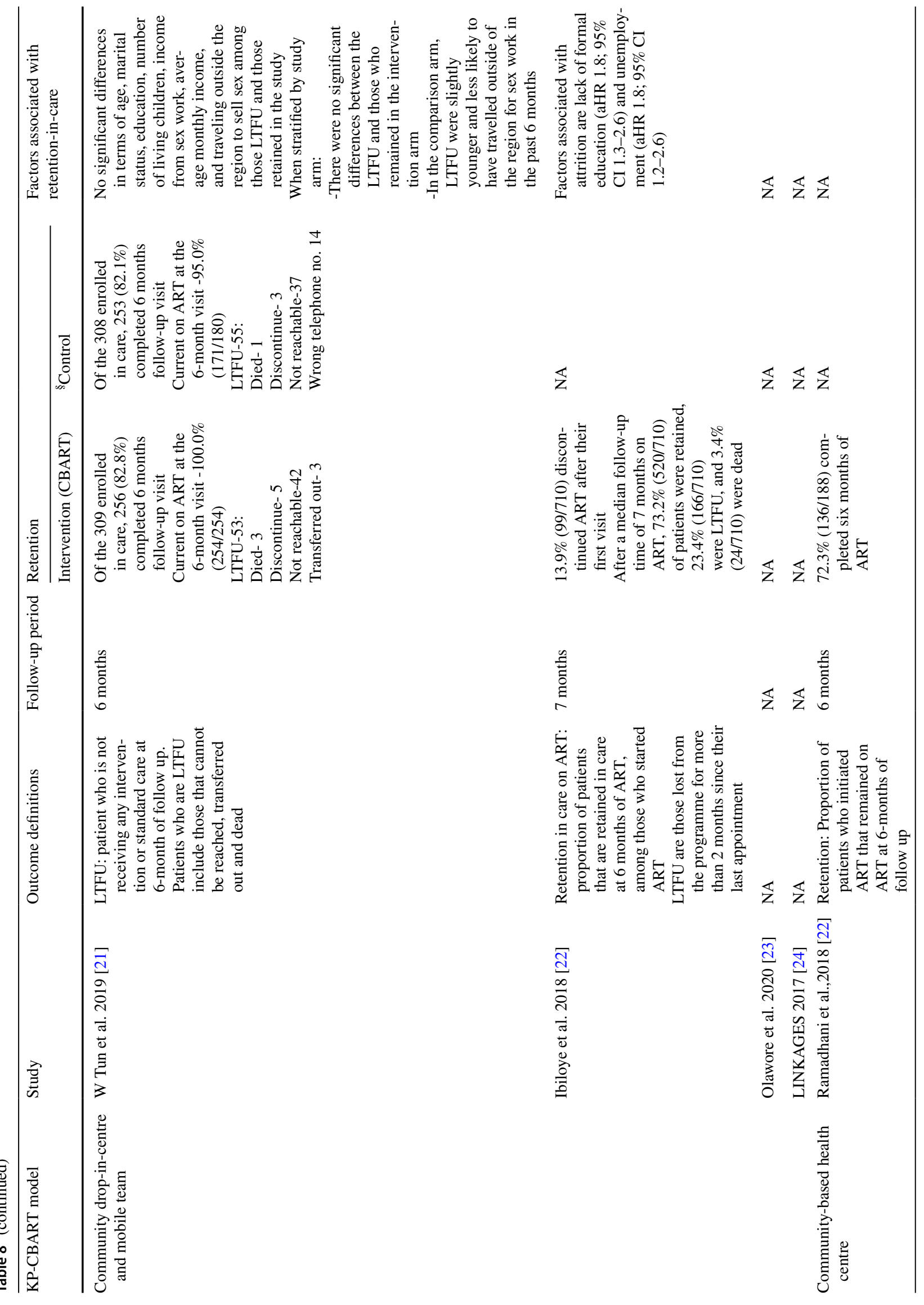




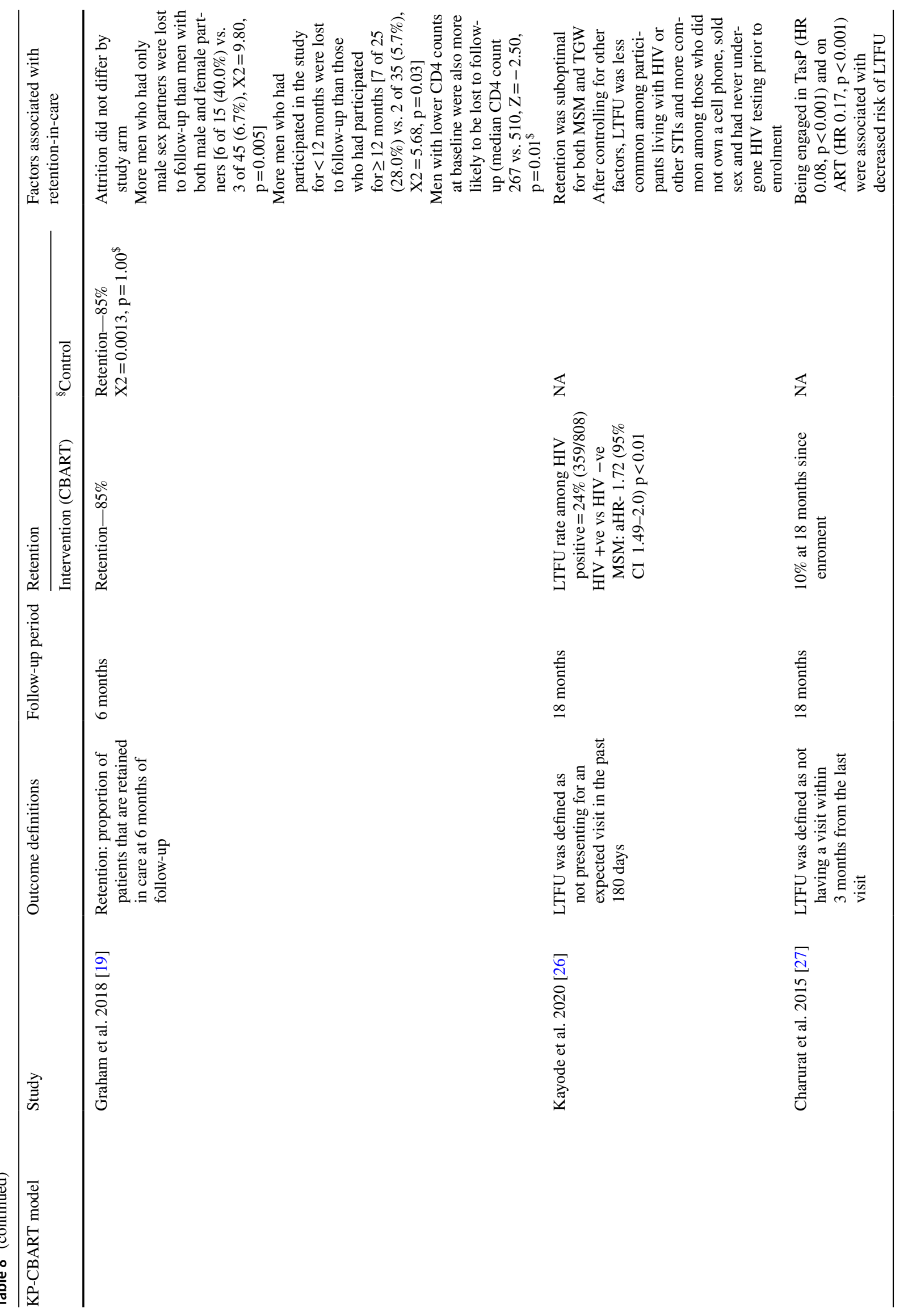




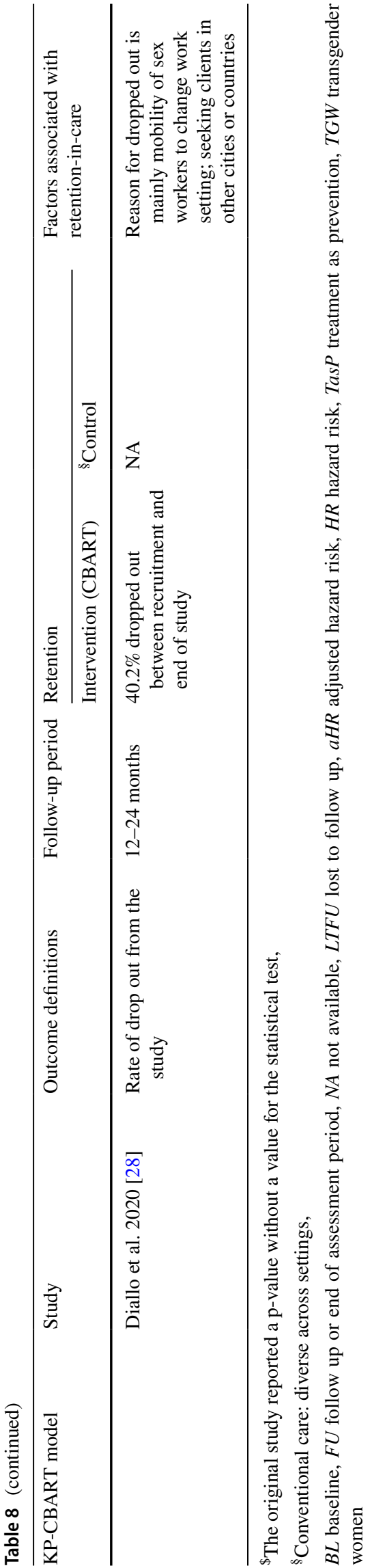

activities that enhance linkage to ART do not always results in an adequate uptake of ART [29].

Our review showed that there are few community-based ART interventions targeting key populations and most were implemented at small scale and in research settings. Three approaches to KP-CBART were described, namely through (a) community drop-in-centres, (b) community drop-in-centres plus outreach through a mobile team or (c) communitybased ART centres. What differentiates these models from each other are the locations of service delivery, the roles of care providers in ART delivery, and the package of HIV services offered to KP. From the present review it is not possible to infer which model works best for which population or setting. Already planned research of the existing KP-CBART programmes using realist evaluation will provide more evidence on the contextual factors and types of CBART model that favour good treatment outcomes.

CBART models were designed to meet the needs of KP communities, by attempting to reduce or dampen the effect of known socio-cultural and health system barriers to HIV prevention and treatment services [11]. The community drop-in-centre provides opportunities for members of KP to meet and give support to each other; and at the same time, to access HIV prevention and treatment services. Formation of support groups or buddy systems may be another critical element that contributed to engagement in care and medication adherence in the KP-CBART programmes [30]. For example in the Sisters programme, a trusted partner or sister is paired with a FSW, who is on ART or pre-exposure prophylaxis. These 'partners' act for each other as treatment buddies and they attend support group meetings together and remind one another of ART appointments [18]. The Shikamana project in Tanzania established Loans and Savings Support group to empower FSWs [17]. Through financial support and training, FSWs were empowered to take financial responsibility for their health (nutrition, transportation, and etc.). Moreover, KP were engaged in a large variety of tasks [17].

KP were trained as peer educators to support HIV service delivery $[17,19,21,24]$. The involvement of KP as care providers in CBART may have facilitated HIV service delivery because they were able to understand the needs of the KP community better and their peers trust them more. With appropriate training and supervision, task-shifting of medical tasks such as ART refill is possible. Provision of peer-support and health navigation can improve engagement throughout the continuum of HIV care and treatment [31]. There is need to understand the causative mechanisms for observed outcomes in KP-CBART, as perceived by the participants, and the context conditions under which this works. How the involvement of KP in care provision was perceived by KP-CBART stakeholders has not been documented. Whether KP involvement indeed increases the acceptability of HIV service utilisation, needs to be assessed by future 
Fig. 1 Prisma diagram of literature search for KP-CBART study and selection process

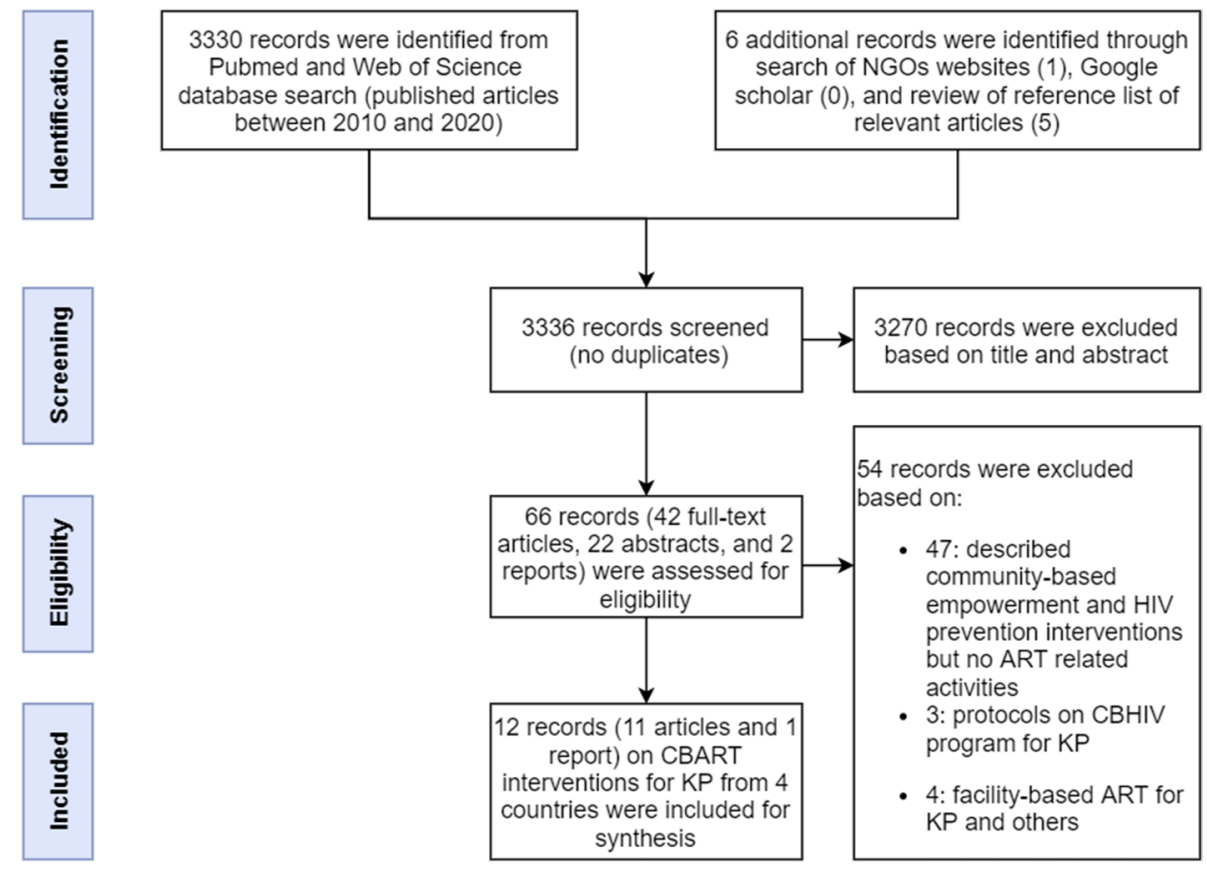

studies, as well as the extent to which KP can be involved in tasks traditionally performed by medical professionals.

Another hypothesis that needs further empirical testing in different settings is that the increase in HIV case identification in KP-CBART programmes/through the KP CBART service delivery model is probably due to sensitisation and activities of the outreach workers (clinical staff, peer educators) in the programme, illustrating the importance of providing a comprehensive package of services [32]. Recruitment into the CBART programme was respondent-driven ('snowballing'), a process whereby peer educators were trained to identify and counsel KPs within their network and as such enhance HIV testing and ART enrolment [18, 21]. In the LINKAGES program, The KP-CBART (EPOA) engaged HIV-positive KPs as "peer mobilisers" in hotspots to mobilise and convince peers in their network for HIV testing and linkage to ART [23, 24]. This approach offers an opportunity for strategic HIV testing and could be leveraged to provide social network and index testing to KP. The high HIV positivity rates reported in this review are similar to findings from studies on social network and index testing [33]. Unlike the KP-CBART, most CBART models in the general population (GP-CBART) do not include HIV testing services, because only clinically stable HIV positive clients are enrolled into the models. Those who test positive to HIV in the KP-CBART, are either referred for ART or onsite ART initiation is offered depending on the type of model.

Where measured, linkage to HIV care and ART uptake also improved in the KP-CBART programmes compared to the baseline [17] and was better or similar to findings in the facility-based care [21]. The mobile health teams offer HIV counselling and testing, ART (both referral and initiation) in outreach venues or hotspots and home based platforms. In situations where ART initiation is not possible, potential clients were referred with an escort to a drop-in-centre with ART capacity or to a health facility for ART initiation.

ART uptake in the community-based health centre for MSM in the Nigeria study was remarkably lower (50.1-54.7\%\%) compared to the other two models [25, 26]. The difference in population type (MSM vs FSW) and the lower level of involvement of MSM in HIV service delivery may explain the low ART uptake in the community-based health centre model.

The rates of adherence to medication and retention in care (Tables 5 and 7) in CBART models are comparable to conventional HIV care (Table 7). Evidence [17] suggests that retention in care is correlated with the age of patients and level of education showing that there is need to address the social determinants of health among the KP to further improve their engagement in care.

Where measured, KP receiving ART through the CBART programme, achieved a similar viral suppression rate compared to those in the standard care model [17, 18]. However, viral suppression rate is still lower than the UNAIDS 95:95:95 target [34]. To improve access to viral load testing and increase viral suppression rates among $\mathrm{KP}$, there is need to improve on logistics for viral load testing to reduce the turn-around time for viral load test result in the HIV programmes [35]. KP peers can assist with viral load sample collection and transfer from outreach venues, hotspots and drop-in-centres to PCR laboratories. If case management and medical tasks can effectively be shifted to community 
members such as trained KP, comprehensive KP-CBART programme may become more sustainable [16].

The major difference between CBART organised for PLHIV in the general population and KP-CBART is that the care package was more comprehensive in KP-CBART models, and that the role of lay health workers and peers was not limited to counselling and ART refill. In the trained KP-CBART service delivery model, trained peer educators participated in a wide range of activities, such as ART outreach (mobilising for HIV testing and ART), distribution of condoms, tracking LTFU, referral for ART initiation, and ART initiation. For example, in the Tanzania study, the peer educators and other members of the mobile health team initiated HIV positive FSW on ART. It was not clear for this intervention which type of training peer educators received and how much and what kind of support they received when initiating ART [21].

KP-CBART models can be adapted to lessons learnt from CBART for general population and vice versa. A review of CBART for the general population concluded that clinical outcomes for participants on treatment were at least comparable with facility-based ART and are likely to be costeffective [36]. KP-CBART share some similarity with differentiated service delivery (DSD) models for the general population, howbeit a lot of lessons and best practices can be learnt from DSD models implementation in the general population (GP). DSD models among the GP include clientmanaged, health care worker-managed and out-of-facility (individual) models [37, 38]. Similarities and differences between KP-CBART models and CBART for the general population is shown in Supplementary Table 1).

When compared one-to-one with facility-based care in the RCT, outcomes in KP-CBART were at least as good. Compared to baseline, KP-CBART improved the continuum of HIV care and treatment outcomes across different settings in sub-Saharan Africa (Tanzania, Nigeria, Zimbabwe and Cote d'Ivoire) [17, 18, 21, 22, 24]. However, this does not imply that all HIV care should be community-based and by KP community members. CBART and conventional facility-based HIV care are likely to have complementary effects, as they meet the needs of different populations. Both approaches are needed to meet the UNAIDS 95-95-95 targets $[1,7]$. KPs may access ART care in conventional health facilities and achieve optimal treatment outcomes if barriers to care are minimised. KP-CBART can complement facility-based care by offering ART services to those who cannot access care in the regular health facilities. Therefore, national HIV programmes and HIV programme managers should promote KP-friendly facility-based care alongside KP-CBART to maximize access to HIV care/tailor service delivery models according to actual needs and context.

The summary of strength and limitations of studies included in this review is presented in
Table 9. Community-based ART interventions described in this review mainly apply to FSW. Six of the twelve reports described CBART programs for FSW, two reported data for both FSW and MSM, while four reports showed data from MSM. No study specifically target PWID and transgender people. This limits the generalisability of the findings from this review to specific KP subgroups. The heterogeneity of CBART interventions and study designs did not favour conducting a meta-analysis. With increasing evidence on KPCBART, future research should consider a systematic review with metaanalysis to provide a more superior evidence on the models. While acknowledging these limitations of our study, a strength of this review was the systematic approach to the review following the PRISMA ScR guidelines. The evidence reported here seems robust, as findings from both randomised and observational studies showed similar effects of KP-CBART on outcomes along the HIV care continuum. Moreover, the observational studies (non-experimental design) of KP-CBART offer evidence from real-life situations that could inform adaptation and scale-up of similar KP-CBART initiatives in sub-Saharan Africa. This review revealed lack of data on contextual factors and mechanisms that trigger observed outcomes. Therefore further operational research is recommended to better understand the effect of contextual conditions on the implementation of CBART for KP in real world settings, and how KP-CBART may be best adapted to fit the specific needs of clients.

\section{Conclusions}

The results from the various studies in sub-Saharan Africa showed the potential of community-based ART delivery to improve engagement in HIV care and ART related outcomes among KP in Africa. Across studies that compared KP-CBART with facility-based care, outcomes in terms of ART uptake, adherence to ART, retention in care and viral suppression were at least as good in KP-CBART as those obtained for KP in facility-based care. Therefore, to fast track the achievement of the UNAIDS 95-95-95 target by 2030 in sub-Saharan Africa, national programmes should promote policies/develop/pilot guidelines on task shifting of medical tasks to members of KP and lay healthcare workers to enrol additional KP in care, providing an alternative model to facility-based care. When community-based ART service delivery for KP would be scaled up to complement facility-based care, future research should focus on longterm benefits of community-based care and explore views, experiences, and preferences of different stakeholders with regards to different community and facility-based models of care, and the mix of differentiated service delivery models in different settings. 
Table 9 Summary of strength and limitations of studies included in the review

\begin{tabular}{ll}
\hline Study & Strength \\
\hline Kerrigan et al. 2019 [17] & $\begin{array}{c}\text { Cluster randomised controlled study [2 clusters, rand- } \\
\text { omized by community] }\end{array}$ \\
Cowan et al. 2018 [18] & $\begin{array}{l}\text { Cluster randomised controlled study (14 clusters, rand- } \\
\text { omized by sites) } \\
\text { An integrated and prospective assessment was done } \\
\text { alongside the trial to better understand strengths and } \\
\text { weaknesses of the programme implementation }\end{array}$
\end{tabular}

Limitations

Limited ability to draw inferences to wider FSW popula-

tion

- Small sample size

- Limited number of communities

Observation bias-no blinding

- Cohort effect: monthly contact with participants to ensure retention

Limitations to assessment of causality:

- Not all potentially confounding factors were overcome by randomization: other interventions (such as microplanning) are linked to outcomes were more frequent in the intervention arm as compared to the control group

- Short duration of intervention makes it difficult to demonstrate effect at the population level

- Randomization at community level: secondary outcomes are dependent on the characteristics of participants in the community, and communities differed

Selection bias during enrolment- respondent driven sampling through snowballing (difficulty in determining the refusal rates)

Cross-over effect: intervention could change the network structures in the control group

W. Tun et al. 2019 [21] Prospective cohort study: good data

Real world setting

- Transferability of findings

- May inform scale-up

One region had the intervention, one region acted as control group. The intervention was not randomly assigned, which reduced the comparability of study arms (confounding bias may have occurred)

Observation/information bias

- Treatment outcomes were self-reported (social desirability bias may have occured)

Ibiloye et al. 2018 [22] Real-world setting

Short study period

Transferability of findings

- Data were collected from a single setting

Retrospective study design may have caused selection bias

Olawore et al. 2020 [23] Real-world settings

- Use of program data with inherent data inconsistencies and missing data

- Monetary incentives were given and could have introduced participation bias

- Recall and social desirability biases

Report is based on program data (missing data)

Report describes \% contribution of intervention to ART care cascades in the program, does not show the actual numbers

Ramadhani et al. 2018 [25] Well established cohort

Attrition bias:

High LTFU among study participants, possibly causing selection bias

Possible re-structuring of patients' social network following HIV diagnosis

Graham et al. 2018 [19] Randomised controlled trial

Study was conducted in a controlled environment, thus may not reflect reality in low resourced setting

Follow-up was limited to 6 months

Results cannot be generalized to the broader population of Kenyan GBMSM because men who participated in this study may differ from other HIV-positive GBMSM in Kenya

Kayode et al. 2020 [26] Prospective cohort, thus reducing incomplete data

Under/over estimate of overall LTFU due to silent transfer (inability to assess whether lost participants re-engaged in care)

Study was conducted in two cities and may not be generalizable to other areas in Nigeria 
Table 9 (continued)

\begin{tabular}{|c|c|c|}
\hline Study & Strength & Limitations \\
\hline Charurat et al. 2015 [27] & Prospective cohort & Selection bias from respondent driven sampling \\
\hline Napierala et al. 2018 [20] & Large cohort & $\begin{array}{l}\text { Selection bias as a result of respondent driven sampling } \\
\text { Reporting bias: self report of HIV status }\end{array}$ \\
\hline Diallo et al. 2020 [28] & Prospective cohort & $\begin{array}{l}\text { Reduction in the power of the study due to high rate of } \\
\text { participants' drop outs from the study } \\
\text { Self-reporting of medication adherence is limited by } \\
\text { social desirability and recall bias }\end{array}$ \\
\hline
\end{tabular}

Supplementary Information The online version contains supplementary material available at https://doi.org/10.1007/s10461-021-03568-3.

Author Contributions OI and TD: conceptualisation of the study, literature search, data analysis, interpretation of data, writing, and review of the original manuscript. CM, JVO, SVB, PJ and LL reviewed the manuscript.

Funding The first Author (OI) received a PhD scholarship grant from the Institute of Tropical Medicine, Antwerp supported by the Belgian Directorate General for Development (DGD). The funder had no role in the conceptualisation, study design, data collection, analysis, data interpretation, and in the writing of the manuscript.

Data Availability Not applicable.

Code Availability Not applicable.

\section{Declarations}

Conflict of interest The authors declare no competing interests.

Ethical Approval Not applicable.

Consent to Participate Not applicable.

Consent for Publication Not applicable.

Open Access This article is licensed under a Creative Commons Attribution 4.0 International License, which permits use, sharing, adaptation, distribution and reproduction in any medium or format, as long as you give appropriate credit to the original author(s) and the source, provide a link to the Creative Commons licence, and indicate if changes were made. The images or other third party material in this article are included in the article's Creative Commons licence, unless indicated otherwise in a credit line to the material. If material is not included in the article's Creative Commons licence and your intended use is not permitted by statutory regulation or exceeds the permitted use, you will need to obtain permission directly from the copyright holder. To view a copy of this licence, visit http://creativecommons.org/licenses/by/4.0/.

\section{References}

1. WHO. Consolidated guidelines on HIV prevention, diagnosis, treatment and care for key populations. Geneva: WHO; 2016.

2. UNAIDS. Worldwide, more than half of new HIV infections now among key populations and their sexual partners. UNAIDS; 2020. https://www.unaids.org/en/resources/presscentre/featurestories/ 2019/november/20191105_key-populations

3. UNAIDS. AIDSinfo. UNAIDS. https://aidsinfo.unaids.org/. Accessed 15 May 2020

4. Avert. HIV and AIDS in East and Southern Africa regional overview. 2019. https://www.avert.org/professionals/hiv-aroundworld/sub-saharan-africa/overview. Accessed 14 May 2020

5. Avert. HIV and AIDS in West and Central Africa overview. 2019. https://www.avert.org/hiv-and-aids-west-and-central-africa-overv iew. Accessed 14 May 2020

6. The GlobalFund. Key populations - the global fund to fight AIDS, tuberculosis and Malaria. 2019. https://www.theglobalfund.org/ en/key-populations/. Accessed 20 Apr 2020

7. Macdonald V, Verster A, Baggaley R. A call for differentiated approaches to delivering HIV services to key populations. J Int AIDS Soc. 2017;20(Suppl 4):28-31. https://doi.org/10.7448/IAS. 20.5.21658.

8. Decroo T, Telfer B, Das DC, White RA, Dos SN, Mkwamba A, et al. Effect of community ART groups on retention-in-care among patients on ART in Tete Province, Mozambique: A cohort study. BMJ Open. 2017. https://doi.org/10.1136/bmjop en-2017-016800.

9. MacPherson P, Lalloo DG, Webb EL, Maheswaran H, Choko AT, Makombe SD, et al. Effect of optional home initiation of HIV care following HIV self-testing on antiretroviral therapy initiation among adults in Malawi: a randomized clinical trial. JAMA - J Am Med Assoc. 2014;312(4):372-9.

10. Decroo T, Van Damme W, Kegels G, Remartinez D, Rasschaert F. Are expert patients an untapped resource for ART provision in Sub-Saharan Africa? AIDS Res Treat. 2012. https://doi.org/10. 1155/2012/749718.

11. Mukherjee JS, Barry D, Weatherford RD, Desai IK, Farmer PE. Community-based ART programs: sustaining adherence and follow-up. Curr HIV/AIDS Rep. 2016;13:359-66.

12. HIV Care Continuum. HIV.gov. https://www.hiv.gov/federal-respo nse/policies-issues/hiv-aids-care-continuum. Accessed $25 \mathrm{Mar}$ 2021

13. Atuhaire L, Adetokunboh O, Shumba C. Effect of female sex work targeted community-based interventions along the hiv treatment cascade in sub-saharan Africa: a systematic review and meta-analysis. BMJ Open. 2020. https://doi.org/10.21203/rs.3.rs-112779/ v1.

14. Arksey H, O'Malley L. Scoping studies: towards a methodological framework. Int J Soc Res Methodol Theory Pract. 2005;8(1):19_ 32. https://doi.org/10.1080/1364557032000119616.

15. Tricco AC, Lillie E, Zarin W, O'Brien KK, Colquhoun H, Levac $\mathrm{D}$, et al. PRISMA extension for scoping reviews (PRISMA-ScR): checklist and explanation. Ann Intern Med. 2018;169:467-73.

16. Decroo T, Rasschaert F, Telfer B, Remartinez D, Laga M, Ford N. Community-based antiretroviral therapy programs can overcome barriers to retention of patients and decongest health 
services in sub-Saharan Africa: a systematic review. Int Health. 2013;5(3):169-79.

17. Kerrigan D, Mbwambo J, Likindikoki S, Davis W, Mantsios A, Beckham SW, et al. Project Shikamana: community empowerment-based combination HIV prevention significantly impacts HIV incidence and care continuum outcomes among female sex workers in Iringa, Tanzania. J Acquir Immune Defic Syndr. 2019;82(2):141-8.

18. Cowan FM, Davey C, Fearon E, Mushati P, Dirawo J, Chabata $\mathrm{S}$, et al. Targeted combination prevention to support female sex workers in Zimbabwe accessing and adhering to antiretrovirals for treatment and prevention of HIV (SAPPH-IRe): a clusterrandomised trial. Lancet HIV. 2018;5(8):e417-26.

19. Graham SM, Micheni M, Chirro O, Nzioka J, Secor AM, Mugo $\mathrm{PM}$, et al. A randomized controlled trial of the shikamana intervention to promote antiretroviral therapy adherence among gay, bisexual, and other men who have sex with men in kenya: feasibility, acceptability, safety and initial effect size. AIDS Behav. 2020;24(7):2206.

20. Napierala S, Chabata ST, Fearon E, Davey C, Hargreaves J, Busza $\mathrm{J}$, et al. Engagement in HIV care among young female sex workers in Zimbabwe. J Acquir Immune Defic Syndr. 2018;79(3):358-66.

21. Tun W, Apicella L, Casalini C, Bikaru D, Mbita G, Jeremiah K, et al. Community-based antiretroviral therapy (ART) delivery for female sex workers in Tanzania: 6-month ART initiation and adherence. AIDS Behav. 2019;23(Suppl 2):142-52.

22. Ibiloye O, Decroo T, Eyona N, Eze P, Agada P. Characteristics and early clinical outcomes of key populations attending comprehensive community-based HIV care: Experiences from Nasarawa State, Nigeria. PLoS ONE. 2018;13(12):e0209477. https://doi.org/ 10.1371/journal.pone.0209477.

23. Olawore O, Astatke H, Lillie T, Persaud N, Lyons C, Kamali $\mathrm{D}$, et al. Peer recruitment strategies for female sex workers not engaged in HIV prevention and treatment services in cote d'ivoire: program data analysis. JMIR Public Heal Surveill. 2020;6(4):93-104.

24. LINKAGES. Accelerating the implementation and scale-up of comprehensive programs for HIV prevention, diagnosis, treatment and care for key populations LINKAGES approach and lessons learned. 2017. https://www.fhi360.org/sites/default/files/media/ documents/resource-linkages-accelerating-implementation.PDF. Accessed 17 May 2020

25. Ramadhani HO, Ndembi N, Nowak RG, Ononaku U, Gwamna $\mathrm{J}$, Orazulike I, et al. Individual and network factors associated with HIV care continuum outcomes among nigerian msm accessing health care services. J Acquir Immune Defic Syndr. 2018;79(1):e7-16. https://doi.org/10.1097/QAI.0000000000 001756.

26. Kayode BO, Mitchell A, Ndembi N, Kokogho A, Ramadhani HO, Adebajo S, et al. Retention of a cohort of men who have sex with men and transgender women at risk for and living with HIV in Abuja and Lagos, Nigeria: a longitudinal analysis. J Int AIDS Soc. 2020;23(Suppl 6):e25592.
27. Charurat ME, Emmanuel B, Akolo C, Keshinro B, Nowak RG, Kennedy S, et al. Uptake of treatment as prevention for HIV and continuum of care among HIV-positive men who have sex with men in Nigeria. J Acquir Immune Defic Syndr. 2015;68(Suppl 2):S114-23. https://doi.org/10.1097/QAI.0000000000000439.

28. Diallo M, Béhanzin L, Guédou FA, Geraldo N, Goma-Matsétsé E, Kania D, et al. HIV treatment response among female sex workers participating in a treatment as prevention demonstration project in Cotonou, Benin. PLoS ONE. 2020;15(1):e0227184.

29. Njau B, Damian DJ, Abdullahi L, Boulle A, Mathews C. The effects of HIV self-testing on the uptake of HIV testing, linkage to antiretroviral treatment and social harms among adults in Africa: a systematic review and meta-analysis. PLoS ONE. 2021;16(1):e0245498. https://doi.org/10.1371/journal.pone.02454 98.

30. Mukumbang FC, Marchal B, Van Belle S, van Wyk B. A realist approach to eliciting the initial programme theory of the antiretroviral treatment adherence club intervention in the Western Cape Province, South Africa. BMC Med Res Methodol. 2018;18(1):47. https://doi.org/10.1186/s12874-018-0503-0.

31. Lancaster KE, Cernigliaro D, Zulliger R, Fleming PF. HIV care and treatment experiences among female sex workers living with HIV in sub-Saharan Africa: a systematic review. Afr J AIDS Res. 2016;15(4):377-86. https://doi.org/10.2989/16085906.2016. 1255652.

32. Sharma M, Ying R, Tarr G, Barnabas R. Systematic review and meta-analysis of community and facility-based HIV testing to address linkage to care gaps in sub-Saharan Africa. Nature. 2015;528(7580):S77-85.

33. McCree DH, Millett G, Baytop C, Royal S, Ellen J, Halkitis PN, et al. Lessons learned from use of social network strategy in HIV testing programs targeting African American men who have sex with men. Am J Public Health. 2013;103(10):1851.

34. Pustil R. Global AIDS. AIDS. 2016;17(Suppl 4):S3-11.

35. World Health Organization. Technical and operational considerations for implementing HIV viral load testing. 2014. pp. 1-24 www.who.int. Accessed 5 Apr 2021

36. Nachega JB, Adetokunboh O, Uthman OA, Knowlton AW, Altice FL, Schechter M, et al. Community-based interventions to improve and sustain antiretroviral therapy adherence, retention in HIV care and clinical outcomes in low- and middle-income countries for achieving the UNAIDS 90-90-90 targets. Curr HIV/ AIDS Rep. 2016;13:241-55.

37. Health care worker-managed group. http://www.differentiatedcare. org/Models/HealthCareWorkerManagedGroup. Accessed 26 May 2020

38. Out-of-facility individual. http://www.differentiatedcare.org/Models/OutOfFacilityIndividual. Accessed 26 May 2020

Publisher's Note Springer Nature remains neutral with regard to jurisdictional claims in published maps and institutional affiliations. 